\title{
Time and scale in Life Cycle Assessment: the case of fuel choice in the transport sector
}

\author{
Environmental Systems Analysis, \\ Department of Energy and Environment, \\ Chalmers University of Technology, \\ SE-412 96 Göteborg, Sweden \\ E-mail: karl.hillman@chalmers.se \\ E-mail: bjorn.sanden@chalmers.se \\ *Corresponding author
}

Karl M. Hillman* and Björn A. Sandén

\begin{abstract}
Life Cycle Assessments (LCA, including Well-to-Wheel studies) that are to support decisions that strive to change large technical systems need to consider time and scale related factors, which are given little attention in standard LCA procedures. Here, we address three issues and provide examples from the case of alternative fuels. First, shifting time frame gives room for technical development that should affect not only the choice of performance data, but perhaps also the functional unit and the selection of technologies under study. Secondly, background systems, such as heat and power production, change over time and increased production volumes of the alternative fuel change the transport system that is used to produce transport fuel. We show that such changes have consequences not only for Greenhouse Gas (GHG) emissions from each fuel-chain, but also for the ranking order of, e.g. Rapeseed Methyl Esther (RME) and ethanol in terms of GHG emissions. Finally, different types of feedstock are available in different quantities and different by-product markets vary in size. Key markets for RME by-products in EU correspond to an RME production that covers about 3\% of transport fuel demand. Consequently, GHG emissions that are allocated to the fuel should change with the scale of adoption.
\end{abstract}

Keywords: biofuels; ethanol; Life Cycle Assessment; LCA; Rapeseed Methyl Esther; RME.

Reference to this paper should be made as follows: Hillman, K.M. and Sandén, B.A. (2008) 'Time and scale in Life Cycle Assessment: the case of fuel choice in the transport sector', Int. J. Alternative Propulsion, Vol. 2, No. 1, pp. 1-12.

Biographical notes: Karl M. Hillman's (LicEng, MSc) research revolves about environmental assessment methodologies (mainly Life Cycle Assessment, LCA) and technical change processes, and how emerging technologies could be assessed regarding their contribution to long-term environmental improvements. During his $\mathrm{PhD}$, he has focused on alternative transport fuels and vehicles.

Björn A. Sandén's (Associate Professor) research areas include environmental assessment of emerging energy and transport technologies (including Life Cycle Assessment (LCA) and other systems approaches) and innovation system studies, i.e. analyses of the drivers and barriers of technical change. He is a member of Chalmers Centre for Energy Research (CEC) and Chalmers Innovation Centre (RIDE).

Copyright (C) 2008 Inderscience Enterprises Ltd. 


\section{Introduction}

While economic growth increases the demand for energy services, the carbon dioxide emissions inherently linked to current fossil fuel energy technologies need to be reduced substantially over the century to "prevent dangerous anthropogenic interference with the climate system" (UNFCCC, 1992). As a consequence, there will be a need for development and large-scale diffusion of a range of new technologies based on renewable energy for conversion, storage, transport and efficient use of energy.

Road transportation is currently responsible for $20-25 \%$ of world $\mathrm{CO}_{2}$ emissions and is to more than $99 \%$ dependent on fossil oil (IEA, 2000). To reduce oil dependence and Greenhouse Gas (GHG) emissions, different policies are now being implemented to increase the share of motor fuels based on renewable energy. In the short term, the EU directive on the promotion of the use of biofuels or other renewable fuels for transport forces the member states to set targets for the minimum use of renewable fuels (EU, 2003a). The reference value is $2 \%$ by the end of 2005 and $5.75 \%$ by the end of $2010 .{ }^{1}$ For the medium term, the European Council has decided on a binding minimum target of $10 \%$ for all member states (EU, 2007).

Several different fuels are proposed as alternatives to petrol and diesel, e.g. ethanol, FAME, methanol, DME, Fischer-Tropsch diesel, natural gas, biogas and hydrogen. The visions of the future importance of different fuels vary greatly, especially in the medium term (2020) (COWI and NOVEM, 2004). The fuels differ regarding resource base, energy efficiency, environmental impact, technology status and requirements for system change.The introduction (or opposition to introduction) of a fuel is often motivated with support from some kind of environmental systems analysis. Different analyses give different recommendations. ${ }^{2}$

The type of environmental assessment that is most commonly used is Life Cycle Assessments (LCA), in this application often termed Well-to-Tank (WTT) or Well-toWheel (WTW) studies (for an overview, see MacLean and Lave, 2003). ${ }^{3}$

Standard LCA methodology is developed to answer questions about environmental impacts of the current (or historical) production and use of one unit of a product or of minor product or process changes. When this methodology is used to provide answers to questions about strategic technological choices, i.e. not decisions that aim at optimising a process in an existing technological environment, but with the long-term goal of changing large-scale technological systems, the result is of little value and in the worst case interpretations of the result may be grossly misleading. This observation is of particular importance for assessments of GHG emissions resulting from emerging energy and transport technologies. In this paper, we explore some aspects that could improve the usefulness of LCA or WTT studies as a support for strategic technology choice. ${ }^{4}$

\section{Prospective attributional technology LCA}

The LCAs can be categorised in different ways. First, some studies are retrospective, looking back at historic environmental impact, while others are prospective, looking forward and considering effects of different decisions (Tillman, 2000). Retrospective studies are almost always what we here would like to term attributional ('state-oriented'), i.e. they use plant specific or average data to illustrate the life cycle impact of an existing

product. Prospective studies are often consequential ('change-oriented') and use marginal 
data. They answer questions of the type: How will an additional unit of ethanol affect emissions of GHG? But prospective studies could also be attributional comparing not changes on the margin but future states (Curran, Mann and Norris, 2005). We suggest that an additional distinction can me made, that between product and technology LCA, where the former seeks to investigate the impact of a specific production process, plant or product, while the latter is an assessment of a more general technology (Sandén et al., 2005).

Our aim is to develop methodology for technology LCA. In consequential technology LCA a key methodological problem is to select which cause-effect chains that should be included and how to quantify the effects (Sandén, 2004; Jonasson and Sandén, 2007; Sandén and Karlström, 2007). In the following, we will instead focus on prospective attributional technology LCA. Then the key methodological problem is to analyse a relevant state.

The relevant state depends on the character of the problem and technology status. In the case of global warming, local emissions of GHG add to a global stock: there is no correlation between the localisation of GHG emissions and climatic effects, and GHG emissions does not primarily lead to an instant problem, but builds up a problem of climatic change over time. The cumulative emissions over several decades, and not the current emissions, are the main cause of concern. In addition, the penetration of all alternative fuels is currently small and most technologies are immature. For these reasons the current state is not very relevant. A future state with larger scale of adoption of the studied alternative fuel is more relevant. But the future is uncertain. Hence, there is a need to analyse many possible future states and stylised states. ${ }^{5}$ In recent years, a study of various different alternative fuels considered for the future European market (2010 and beyond) has been published (Edwards et al., 2003, 2005, 2006, 2007). The project is a joint evaluation performed by CONCAWE (Oil Companies' European Association for Environment, Health and Safety), EUCAR (European Council for Automotive R\&D) and JRC (Joint Research Centre of the EU Commission). Some of the objectives of the study are to establish a consensual WTW energy use and GHG emissions assessment, and to have the outcome accepted as a reference by relevant stakeholders. Several fuels are included, all with an assumed potential of 5-15\% in 2010-2020.

We use Edwards et al. (2003) data to qualitatively and quantitatively explore how results could change when we change factors that are sensitive to time and scale. For the quantitative assessment wheat ethanol and Rapeseed Methyl Esther (RME) are selected for review, as they are gaining much attention in Europe (COWI and NOVEM, 2004), and they entail interesting by-product and land use aspects. Though still on a pilot scale, methanol from gasification of wood from short rotation forestry is also included in the study, as an example of a future biofuel with higher production efficiency. The environmental indicators studied are GHG emissions (measured in $\mathrm{CO}_{2}$-equivalents ${ }^{6}$ ) and agricultural land use (area measure). In the calculations the Lower Heating Value of fuels and other products was used. Agriculture and market data apply to EU-15.

\section{Some methodological implications}

The methodological implications of introducing the time and scale considerations proposed here are divided into three parts, where the first has to do with choice of data and functional unit, and connections to technical development. Secondly, we analyse 
the influence of the choice of background system used and finally different uses of by-products are studied, and related to feedstock utilisation.

\subsection{Technical change and choice of data, scope and functional unit}

The first and most obvious observation is that technology performance will change over time. Components such as engines and seeds, and processes such as farming and fuel processing become better over time as more knowledge is gained. This factor is not only dependent on time, but also on scale. More production implies more learning and larger scale of production gives room for increased efficiency (see e.g. Moreira and Goldemberg (1999) for an account of technology development in ethanol production in Brazil). An increased scale also generates incentives for system optimisation. Plants dedicated to produce fuel instead of food or paper, engines optimised for a new fuel and vehicles optimised for a new propulsion system will create more efficient systems than those relying on current practices. The implication of this is that data on current performance should be used with care. Assumptions on future performance at different scales of adoption could be enlightened by calculated physical limits, expert estimates, trend extrapolation and experience curves. ${ }^{7}$

Not only data, but also the relevant choice of alternative WTW chains changes over time. In the short term, say within five or even ten years, a lot of things in the WTW chain are fixed. The only real alternatives are fuels that fit into the existing fuel-vehicle system using raw material from established production systems, albeit for other purposes. The most popular fuels that use a renewable energy resource and have these properties are ethanol and FAME from crops. Crops are already produced in large quantities. Ethanol can be used as blends in gasoline or in gasoline engines with some modifications. FAME can be used as blends in diesel or in slightly adjusted diesel engines. But, if we look further into the future, flexibility increases. Over time, farmers can switch to short rotation forestry, and engines and infrastructure could be adapted to, e.g. DME or methanol. Over time, batteries and fuel cells, and solar electricity and hydrogen production could offer realistic ways to provide transport, using a fraction of the land required to produce energy crops. Over time, also other transport modes could open up for new ways of supplying mobility which introduce a vast range of possible and perhaps realistic alternatives to provide a functional unit such as person kilometre or tonne kilometre. In short, many options are not relevant for comparison in the short term, but if the short term is irrelevant, even seemingly farfetched alternatives could be of interest. ${ }^{8}$

Similarly, technical change opens up for radically new functions and combinations. A vehicle with a fuel cell and an electrical engine could, e.g. be constructed in a different way, providing a range of alternative and improved services. It could also be plugged into the electricity grid to supply peak power. How can such new options be taken into account in a comparative study? This indicates the difficulties of specifying relevant and comparable alternatives and functional units.

\subsection{Background systems}

For convenience, the production processes in prospective LCA could be divided into a foreground and a background system, where the foreground system consists of those processes directly affected by decisions based on the study. The background system consists of all other processes included in the study, which indirectly are affected by 
measures taken in the foreground system (Tillman, 2000). Changes in background systems could be divided into those related to time (not affected by the foreground system), e.g. new technology used for heat and electricity production and transition to bio-based input materials, and those related to the scale of penetration of the studied fuel (affected by the foreground system), typically that the fuel is used for its own production and distribution.

To illustrate the impact of such differences, we use the state studied in Edwards et al. (2003) as a base case and compare it with five stylised states with different background systems. The inputs in the base case are diesel, coal, heavy fuel oil, natural gas, the current electricity mix in the EU and input materials (such as methanol and hexane) of fossil origin. We have assumed that all coal, heavy fuel oil and natural gas are used for process heat, and can be replaced by coal in our coal cases and wood from short rotation forestry in our wood cases. Correspondingly, the electricity mix is replaced by electricity from coal in the coal cases and wood in the wood cases.

In Edwards et al. (2003), it is assumed that all inputs of transport fuel that are required to produce biofuels are diesel (Figure 1 , case $\mathrm{I}^{*}$ ). This assumption could possibly be relevant if the task is to estimate a minor change of the current state, but not if the assessment aims at comparing different fuels for strategic purposes. An increased scale of biofuel production implies that more biofuels are also used as inputs. Biofuel use for biofuel production can be taken into account in two different ways (Figure 1, cases I and II). ${ }^{9}$ First, an increased scale of biofuel production can be assumed to lead to a change of the transport background system. Consequently, transport input can be modelled to reflect different biofuel shares $(x)$ and scenarios of increasing shares (Figure 1, case I). For low penetration levels ( $x$ close to 0 ) this general case degenerates to case I*. For $100 \%$ penetration $(x=1)$ only biofuel is used as transport fuel input. In comparison to case $I^{*}$ this leads to an increased demand for other inputs, such as heat and electricity, per functional unit. Case I can be termed a gross output approach. When evaluating WTT environmental impact of a fuel, the results are usually given in emissions and resource use per energy unit of the studied fuel. Consequently one will have to choose if the energy output, the environmental impact relates to, is the gross energy output of the fuel production system or the net output that is left when a part of the gross output is used in fuel production processes (see Figure 1). In the net output approach (case II), the functional unit is MJ of the fuel available for other purposes than producing fuel. In comparison to case I this leads to an additional increased use of other inputs. The net output approach can be used for any scale of biofuel penetration.

Here, we have chosen to use the net output approach since it better reflects the inherent differences between fuels. The influence of this is about $9 \%$ higher emissions and land use per functional unit for wheat ethanol and RME, and 4\% higher for methanol, than if we had used the gross energy approach with $100 \%$ biofuels in the background system. For diesel the effect of choosing the net energy approach is assumed to be small, and is not included in the calculations.

For the purpose of illustration, no by-product credits are included for any of the fuels in this section (this is studied separately in the following section). The states analysed for each fuel are two coal cases, two mixed cases and two wood cases. For each category, the alternatives diesel and the studied biofuel are used for transports related to biofuel production. The results are presented in Figure 2. 
Figure 1 Biofuel use for biofuel production can be taken into account in two different ways: the environmental impact of a fuel can be related to $E_{\text {out, gross }}$ (gross output approach) or $E_{\text {out, net }}$ (net output approach)

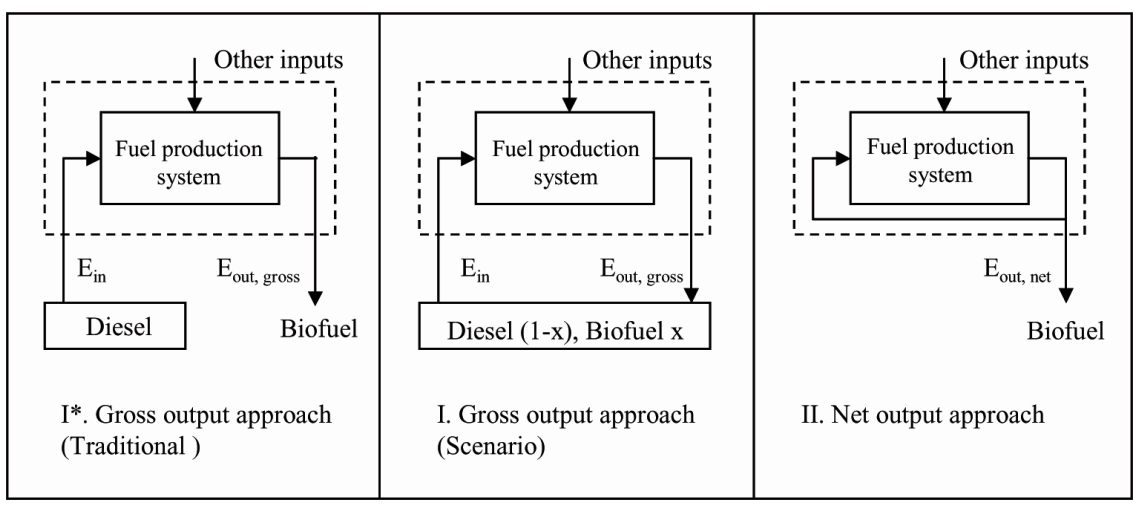

Note: $E_{\text {out, gross }}$ is the energy content in the produced fuel, $E_{\text {in }}$ is the energy content of the fuel used for production and distribution and $E_{\text {out, net }}$ is the energy content of the fuel available for other purposes $\left(E_{\text {out, net }}=E_{\text {out, gross }}-E_{\text {in }}\right)$.

Figure 2 Greenhouse Gas (GHG) emissions and agricultural land use for the coal, mixed and wood cases, in combination with diesel (black dots) and the studied biofuel (white dots)

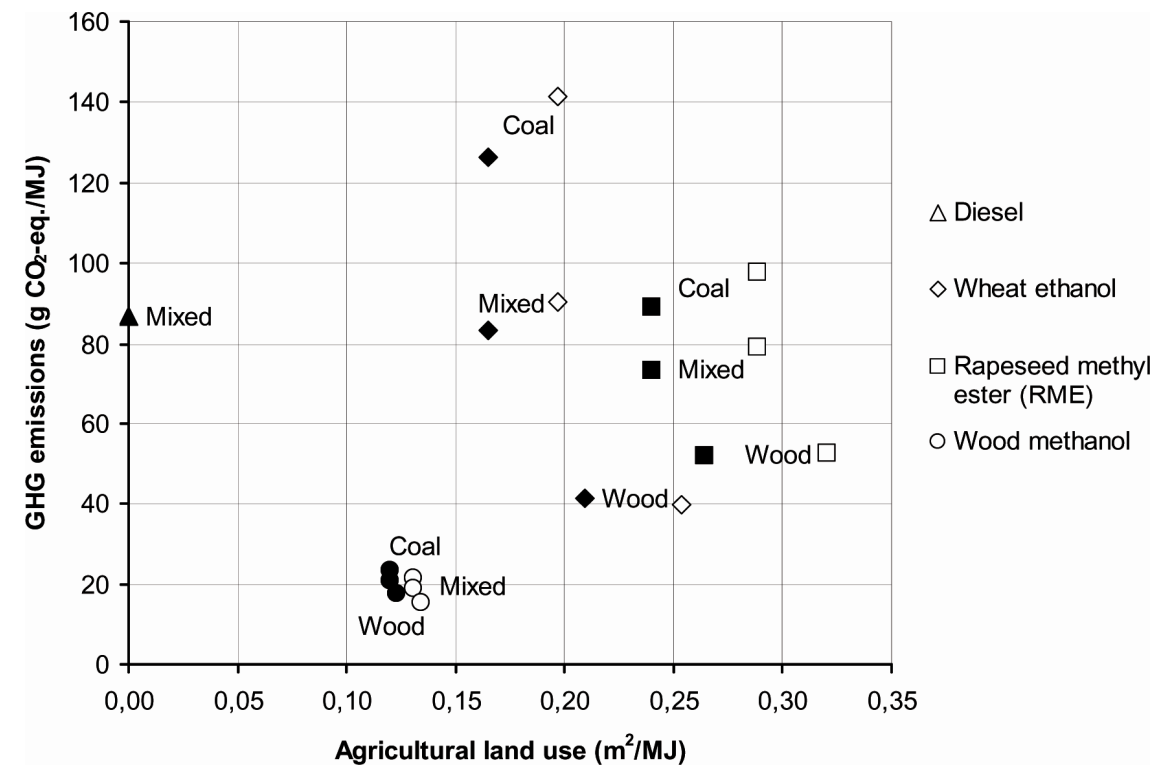

Note: The value for diesel production is shown for comparison.

Clearly, the GHG emissions are highest in the coal cases and lowest in the wood cases for each fuel. There are still some GHG emissions in the wood case with biofuels, because of some input materials based on fossil resources, but mainly due to nitrous oxide $\left(\mathrm{N}_{2} \mathrm{O}\right)$ emissions from soils and production of fertiliser (more than 95\% of the GHG 
emissions).$^{10}$ For high GHG emissions, the emissions increase when replacing diesel with the studied biofuel for process energy and distribution. The reason for this is that the emissions from biofuel production are higher than the emissions from diesel production and use in those cases.

We can see that the GHG emissions are higher for wheat ethanol than for RME in the coal cases, that the difference gets smaller in the mixed cases, and that they are higher for RME in the wood cases. This is due to that RME has a larger share of its GHG emissions from soils. Methanol gives the lowest GHG emissions in all cases.

The differences in agricultural and processing yields give the difference in agricultural land use between the three fuels, where methanol has the lowest and RME has the highest use in each case. Agricultural land use is higher in the wood cases, due to the land needed for forestry to produce heat and electricity. It gets even higher when the studied biofuel is used for biofuel production. A higher land use could be translated into GHG equivalents, if it is assumed that residual land is used for harnessing of energy that can replace fossil fuels in another sector, or replace more transport fuel (see the following section).

\subsection{By-product credits}

The WTT environmental impact of a fuel also depends on the type of feedstock used and the production of by-products. This introduces a different kind of scale dependency. Different types of feedstock (such as waste and farmland) are available in different quantities and different by-product markets vary in size. Here, we illustrate this by giving an example of how by-product credits for RME production in EU-15 could change with the level of market penetration.

For many alternative transport fuels, the production of the fuel will result in one or more by-products that could be used for various purposes. In WTT studies, the environmental impact of the fuel production then has to be allocated between the fuel and its by-products. There are several methods for doing this and in the ISO standard for LCA it is recommended that when inputs and outputs cannot be directly connected to a product, the system should be expanded to include the additional functions related to the by-products (ISO, 2006). If this is not possible, the inputs and outputs should be allocated according to the physical relationships or, e.g. the economic value. In our example, we use the system expansion method, so that credits are given to the fuels for avoided production of the replaced products. ${ }^{11}$

By-products from production of RME are rapeseed meal and glycerine ${ }^{12}$ and we assume that they are used for the functions proposed in Edwards et al. (2003). Rapeseed meal is used here as an ingredient in animal feed products, replacing soya meal as a protein source. Glycerine is used as a chemical, replacing synthetic glycerine or propylene glycol of fossil origin. It could also be used as an ingredient in animal feed products, replacing wheat as a feed energy source. When these higher value markets have been saturated, we assume that both rapeseed meal and glycerine can be used as fuels for heat production. ${ }^{13}$ The transport of by-products is not regarded.

We use the mixed background system with RME used for its own production (net output approach). This means that an increased market penetration of RME does not affect emissions per functional unit from RME production, but only the by-product credits. Similarly, the avoided use of transport fuel for the production of the replaced products are taken into account by increasing net RME output. The by-product heat 
mainly replaces heat from natural gas, both in RME production and in other applications, since natural gas is the dominating fuel for heat production in the mixed case.

Figure 3 presents the by-product credits in terms of decreased GHG emissions and agricultural land use, related to the RME share of petrol and diesel used for transport in EU-15 (EU, 2003b). ${ }^{14}$ Both marginal credit steps and the resulting average credit curves are given. The first step ( $0.9 \%$ penetration) is limited by the market for glycerine replacing synthetic glycerine, the second by glycerine replacing propylene glycol $(2.3 \%)$ and the third by rapeseed meal replacing soya meal in animal feed products $(3.1 \%)$. Up to this point, the GHG emission and land use credits decrease or remain constant with each step. However, when rapeseed meal and later glycerine (at 4.3\%) are started to be used for heat production and substitute natural gas, the GHG emission credit increases, while the marginal land use credit goes to zero.

In the mixed case illustrated here, GHG emissions are minimised if the two by-products are used for heat production replacing natural gas and not for anything else (Figure 4). This would not be the case with a bioenergy background system (as in the wood cases) in which heat from by-products would replace heat from wood. The situation would also change if saved bioenergy feedstock or land is given a GHG credit.

A somewhat extreme example would be that a credit for the saved bioenergy feedstock (soybeans) is calculated by assuming that the soybeans are still produced (no saved land), but combusted to replace natural gas (less GHG emissions). Then the resulting GHG emissions are lower if rapeseed meal is used to replace soya meal instead of natural gas, giving initial steps in Figure 4 with below zero emissions. This is a result of the system expansion method.

Figure 3 By-product GHG emission credits (dotted line) and agricultural land use credits (black line) for both rapeseed meal and glycerine from RME production

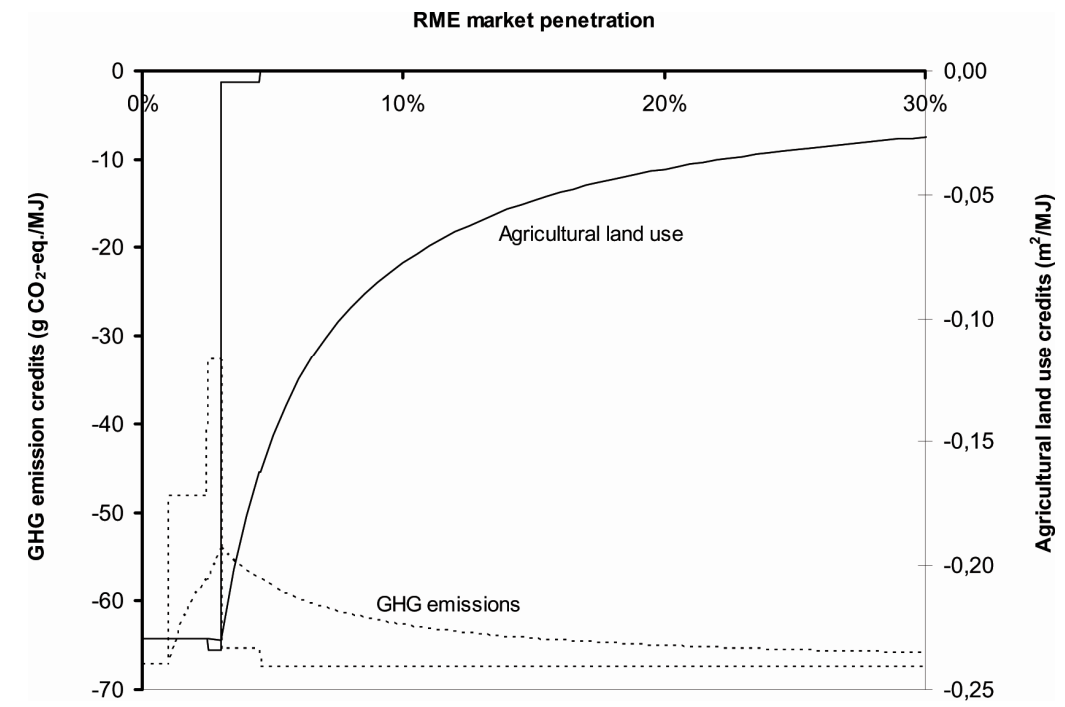

Note: The steps in the figure correspond to different by-product market potentials, measured in percent of petrol/diesel in EU-15 replaced by the RME produced. The smooth lines are the average credits for RME at a certain penetration rate. Negative values mean that the amount can be subtracted from the RME results without allocation (shown in Figure 2). 
Figure 4 GHG emissions (dotted line) and agricultural land use (black line) for RME at different penetration rates, with credits for different uses of by-products considered

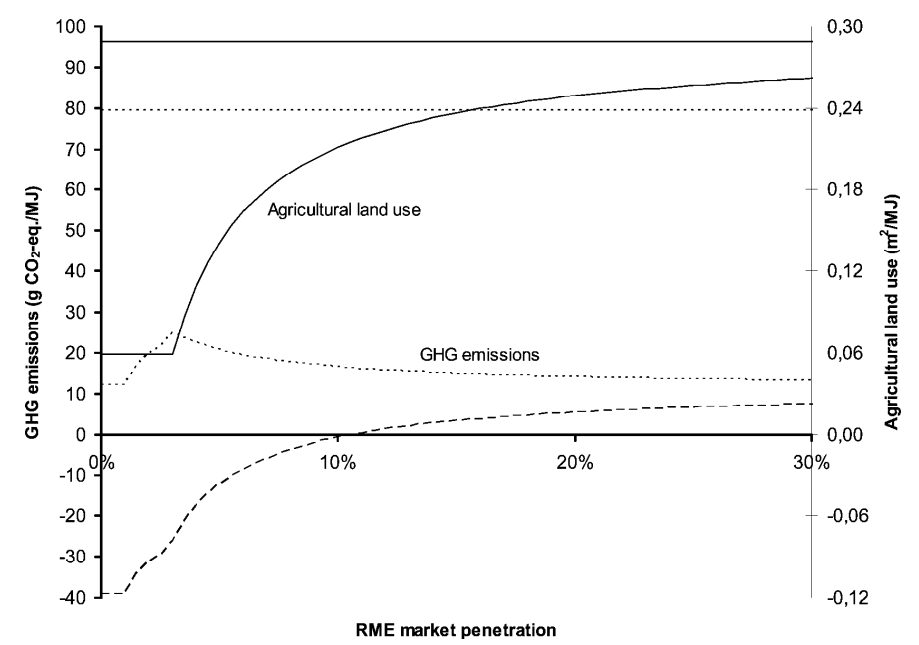

Note: The horizontal lines at $79 \mathrm{~g} \mathrm{CO}_{2}$-equiv. $\mathrm{MJ}^{-1}$ and $0.29 \mathrm{~m}^{2} \mathrm{MJ}^{-1}$ illustrate the $\mathrm{GHG}$ emissions and land use if no by-product credits are considered (see Figure 2). The dashed line shows the resulting GHG emissions when saved agricultural land is used to produce soybeans used for heat production, replacing natural gas. (Below zero emissions is a result of the system expansion method.)

If we look further into the future, referring to the discussion in Section 3.1, soybean farmers could probably switch to more area efficient energy production instead of burning beans. Producing short rotation energy forest on the saved land would produce even higher GHG credits. ${ }^{15}$ On the other hand, if an equal GHG value were given to the land used to grow the rapeseed used for RME production, total GHG emission would rise well above the diesel GHG gas emissions. This reflects the fact that using a given land area to substitute heat from bioenergy for heat from natural gas gives a much larger GHG reduction than using the same area to substitute RME for diesel.

\section{Conclusions}

LCA, including WTW studies that are to support decisions that strive to change large technical systems need to consider time and scale related factors, which are given little attention in standard LCA procedures. We suggest that it is important to look beyond the current situation and study many possible future states or stylised states to explore general technology differences. Here, we have briefly addressed three issues. First, shifting time frame gives room for technical development that should affect not only the choice of performance data, but perhaps also the functional unit and the selection of technologies under study. Secondly, background systems such as heat and power production change over time and increased production volumes of the alternative fuel change the transport system that is used to produce transport fuel. We have shown that such changes have consequences not only for GHG emissions from each fuel-chain, but also for the ranking order of, e.g. RME and ethanol in terms of GHG emissions. Finally, different types of feedstock are available in different quantities and different by-product 
markets vary in size. To give an example, key markets for RME by-products in EU correspond to an RME production that covers about 3\% of demand, i.e. well below the $5.75 \%$ EU target for 2010. Consequently, GHG emissions that are allocated to the fuel should reflect the scale of adoption in the studied state.

\section{Acknowledgements}

Centre for Environmental Assessment of Product and Material Systems (CPM) is thanked for the financial support.

\section{References}

Azar, C., Lindgren, K. and Andersson, B.A. (2003) 'Global energy scenarios meeting stringent $\mathrm{CO}_{2}$ constraints - cost-effective fuel choices in the transportation sector', Energy Policy, Vol. 31, pp.961-976.

COWI and NOVEM (2004) Stakeholder Views on Biofuels - WP1 Final Report about the Results of the Stakeholder Questionnaire. The Netherlands Agency for Energy and the Environment.

Curran, M.A., Mann, M. and Norris, G. (2005) 'The international workshop on electricity data for life cycle inventories', Journal of Cleaner Production, Vol. 13, pp.853-862.

Edwards, R., Griesemann, J-C., Larivé, J-F. and Mahieu, V. (2003) Well-To-Wheels Analysis of Future Automotive Fuels and Powertrains in the European Context. EUCAR, CONCAWE, JRC.

Edwards, R., Larivé, J-F., Mahieu, V. and Rouveirolles, P. (2005) Well-To-Wheels Analysis of Future Automotive Fuels and Powertrains in the European Context. EUCAR, CONCAWE and JRC.

Edwards, R., Larivé, J-F., Mahieu, V. and Rouveirolles, P. (2006) Well-To-Wheels Analysis of Future Automotive Fuels and Powertrains in the European Context. EUCAR, CONCAWE and JRC.

Edwards, R., Larivé, J-F., Mahieu, V. and Rouveirolles, P. (2007) Well-To-Wheels Analysis of Future Automotive Fuels and Powertrains in the European Context. EUCAR, CONCAWE and JRC.

EU (2003a) 'Directive 2003/30/EC of the European Parliament and of the Council - of 8 May 2003 - on the promotion of the use of biofuels or other renewable fuels for transport', Official Journal of the European Union, Vol. L123, pp.42-46.

EU (2003b) Energy: Yearly statistics - Data 2001. Office for Official Publications of the European Communities, Luxemburg.

EU (2007) Brussels European Council 8/9 March 2007 - Presidency Conclusions. Council of the European Union, Brussels, Belgium.

FEFAC (2004) Industrial Compound Feed Production. Retrieved 30 January, 2004. Available at: http://www.fefac.org/html/publications.cfm.

Gielen, D., Fujino, J., Hashimoto, S. and Moriguchi, Y. (2003) 'Modeling of global biomass policies', Biomass and Bioenergy, Vol. 25, pp.177-195.

Hillman, K.M. and Sandén, B.A. (2007) 'Exploring technology paths: the development of alternative transport fuels in Sweden 2007-2020', Technological Forecasting \& Social Change, accepted for publication.

IEA (2000) World Energy Statistics. International Energy Agency (IEA).

IPCC (2001) Climate Change 2001: The Scientific Basis. Contribution of Working Group I to the Third Assessment Report of the Intergovernmental Panel on Climate Change, Cambridge University Press, Cambridge, United Kingdom and New York, NY, USA. 
ISO (2006) Environmental Management - Life cycle assessment - Requirements and guidelines (ISO 14044:2006). European Committee for Standardization.

Johansson, T.B., Kelly, H., Reddy, A.K.N. and Williams, R. (Eds), (1993) Renewable Energy: Sources for Fuels and Electricity. Washington, DC: Island Press.

Jonasson, K.M. and Sandén, B.A. (2004) Time and Scale Aspects in Life Cycle Assessment of Emerging Technologies: Case Study on Alternative Transport Fuels. Chalmers University of Technology, Göteborg, Sweden.

Lantmännen (2004) Erik Lindgren, Kerstin Sigfridsson, Valle Löfgren, Björn Säterby. Personal communication, February 12-16.

MacLean, H.L. and Lave, L.B. (2003) 'Evaluating automobile fuel/propulsion system technologies', Progress in Energy and Combustion Science, Vol. 29, pp.1-69.

Moreira, J.R. and Goldemberg, J. (1999) 'The alcohol program', Energy Policy, Vol. 27, pp.229-245.

Pimentel, D. (2003) 'Ethanol fuels: energy balance, economics, and environmental impacts are negative', Natural Resources Research, Vol. 12, pp.127-134.

Sandén, B.A. (2004) 'Technology path assessment for sustainable technology development', Innovation: Management, Policy \& Practice, Vol. 6, pp.316-330.

Sandén, B.A., Jonasson, K.M., Karlström, M. and Tillman, A-M. (2005) 'LCA of emerging technologies: a methodological framework', Paper presented in the Proceedings of the $L C M$ 2005 - Innovation by Life Cycle Management, Barcelona, Spain.

Sandén, B.A. and Karlström, M. (2007) 'Positive and negative feedback in consequential life-cycle assessment', Journal of Cleaner Production, Vol. 15, pp.1469-1481.

Shapouri, H., Duffield, J.A. and Wang, M. (2002) The Energy Balance of Corn Ethanol: An Update. United States Department of Agriculture, Office of the Chief Economist, Office of Energy Policy and New Uses.

Tefac (2004) Alf Eriksson. Personal communication, February 16.

Tillman, A-M. (2000) 'Significance of decision-making for LCA methodology', Environmental Impact Assessment Review, Vol. 20, pp.113-123.

UNFCCC (1992) United Nations Framework Convention on Climate Change (UNFCCC). Retrieved 2004. Available at: http://unfccc.int.

Weidema, B.P., Ekvall, T., Pesonen, H-L., Rebitzer, G., Sonnemann, G.W. and Spielmann, M. (2004) Scenarios in Life-cycle Assessment. Society of Environmental Toxicology and Chemistry (SETAC), Pensacola FL, USA.

\section{Notes}

${ }^{1}$ The targets refer to the total energy content (lower calorific value) of renewable fuels in relation to petrol and diesel used for transport purposes.

${ }^{2}$ See for example the debate on net energy output from corn ethanol in the USA; see e.g. Shapouri, Duffield and Wang (2002) and Pimentel (2003).

${ }^{3}$ A different type of studies are energy systems models, which aims at finding minimal cost options for allocation of resources and choice of conversion technologies for many end-use sectors under emission constraints; see e.g. Azar, Lindgren and Andersson (2003) and Gielen et al. (2003).

${ }^{4}$ More detailed results are published in a technical report (Jonasson and Sandén, 2004).

${ }^{5}$ By a 'stylised state' we denote an extreme state (e.g. a state where all electricity and heat is produced from coal) that is unlikely to materialise but that could illustrate important technology differences in a clear way. This is similar to the cornerstone scenarios discussed in Weidema et al. (2004), but their approach implies more plausible scenarios. 
${ }^{6} \mathrm{CO}_{2}$-equivalents are calculated from the factors in IPCC (2001) with a 100-year time frame.

${ }^{7}$ Experience curves normally relate unit cost to the volume of cumulative production, but could probably also be used to estimate relationships between cumulative production and performance data.

${ }^{8}$ Using the current technical and economic feasibility in 'the middle of the fuel-vehicle chain' as selection criteria becomes less appropriate if we look further into the future. Instead it probably becomes more fruitful to look at resource efficiency at one end-point and the potential to fulfil needs and solve social problems at the other end-point of the fuel-vehicle chain.

${ }^{9}$ For this purpose, only the energy content of the fuel is regarded, i.e. potential efficiency differences in the vehicles are not included.

${ }^{10} \mathrm{~N}_{2} \mathrm{O}$ emissions from fertiliser production are from the process itself (Edwards et al., 2003). Though not performed in this study, it would be relevant to study alternative processes, as well.

${ }^{11}$ System expansion can be combined here with the attributional approach, as we consider a number of complete future states that are mutually exclusive.

${ }^{12}$ Collection and use of by-products from farming processes are not included in the study.

${ }^{13}$ The (non-heat) markets for the different uses of the by-products rapeseed meal and glycerine are taken from FEFAC (2004) and Tefac (2004). The maximum rapeseed meal and glycerine contents of animal feed products have been estimated from Lantmännen (2004). On a longer term, of course, there is also the possibility that completely new markets for by-products develop.

${ }^{14}$ The figures only reflect changes over scale. The expected increase of total fuel demand over time is not considered here.

${ }^{15}$ Using the land for direct solar energy conversion would in turn lead to an increased area efficiency of at least a factor of ten above what could be reached for bioenergy plantations (Johansson et al., 1993). 